\title{
Portal vein thrombosis in cirrhosis: diagnosis, natural history, and therapeutic challenges
}

\author{
Aikaterini Mantaka, Aikaterini Augoustaki, Elias A. Kouroumalis, Dimitrios N. Samonakis \\ University Hospital of Crete, Heraklion, Crete, Greece
}

\begin{abstract}
Portal vein thrombosis (PVT) is a frequent complication in cirrhosis and its prevalence increases with disease severity. Several factors are involved in the development and progression of PVT. The challenge for the management of PVT is the precise evaluation of the bleeding risk as opposed to life-threatening extension of thrombosis. Nevertheless, the impact on the progression and outcome of liver disease is unclear. A critical evaluation of the available data discloses that treating PVT in cirrhotics is safe and effective. However, there are open issues, such as which anticoagulant could represent a safer therapeutic option, and when and for how long this treatment should be administered to cirrhotic patients with PVT.
\end{abstract}

Keywords Portal vein thrombosis, cirrhosis, direct oral anticoagulants, anticoagulants, bleeding

Ann Gastroenterol 2018; 31 (3): 1-15

\section{Introduction}

Portal vein (PV) thrombosis (PVT) is characterized by interruption of normal blood flow in the PV because of blood clot formation. Thrombophilic conditions, abdominal inflammation, tumorous invasion, and liver cirrhosis are among the most common causes of PVT (Table 1). Less commonly, PVT has been described after bariatric surgery [1,2], radiofrequency ablation (RFA) for hepatocellular carcinoma (HCC) [3], or fine needle aspiration of pancreatic cancer [4].

Pathophysiologically, an imbalance of the hemostatic mechanism (both pro- and anti-coagulant factors) is implicated in thrombus formation and, ultimately, PVT. The prevalence of PVT is higher in the advanced stages of cirrhosis [5-8] and increases in cirrhotic patients with HCC. Improvement in imaging studies, in combination with better awareness amongst clinicians, makes this diagnosis frequent. However, many controversies exist regarding the optimal management.

Yerdel et al [9], in a seminal paper, have classified PVT according to the size and extension of the thrombus as follows:

Department of Gastroenterology and Hepatology, University Hospital of Crete, Heraklion, Crete, Greece

Conflict of Interest: None

Correspondence to: Aikaterini Mantaka, MD, PhD, Department of Gastroenterology, PO Box 1352, 71100 Heraklion, Crete, Greece, e-mail:katmant@gmail.com

Received 25 September 2017; accepted 26 November 2017; published online 3 March 2018

DOI: https://doi.org/10.20524/aog.2018.0245
Grade 1: partial PVT - the thrombus covers less than $50 \%$ of the PV lumen

Grade 2: PV obstruction greater than $50 \%$, or complete occlusion with or without minimal extension into the superior mesenteric vein (SMV)

Grade 3: complete thrombosis of both PVs, thrombus extends to the proximal part of the SMV

Grade 4: complete thrombosis - the PV thrombus affects both the proximal and distal SMV

More recently, the BAVENO VI working group [10] added two more variables for the classification of PVT, apart from the site (trunk, branches or both), the degree (complete or incomplete) and the extent of involvement of the extrahepatic portal venous system. These are the presentation (clinical and radiological features) and the type of underlying liver disease (cirrhosis, non-cirrhotic liver disease, HCC, post-liver transplant). However, even in this classification, there is no comment on the functional consequences of PV occlusion that could have a detrimental effect on liver function. Sarin et al have further proposed a more comprehensive classification system for PVT in cirrhosis, emphasizing PVT functionality (consequences of acute or chronic PV occlusion in diseased or healthy liver) [11].

Hepatologists face dilemmas in clinical practice concerning the management of cirrhotic patients with PVT. To treat or not to treat with anticoagulant agents, what is the least hazardous treatment option in PVT, or the optimal dose, and for how long should it be administered, taking into consideration the bleeding risk in patients with clinically significant portal hypertension? All these questions become more critical in patients awaiting transplantation. Definitive answers concerning the impact of PVT and its prognostic effect on cirrhosis outcome are still needed. 
Table 1 Causes of portal vein thrombosis

\begin{tabular}{|c|c|c|c|c|}
\hline Cirrhosis & Neoplasms & Prothrombotic causes & Inflammatory diseases & Other \\
\hline & & Inherited prothrombotic disorders & & \\
\hline \multirow[t]{13}{*}{ Any cause } & $\begin{array}{l}\text { Hepatocellular carcinoma/ } \\
\text { Hepatobiliary cancer }\end{array}$ & Factor V Leiden mutation & Diverticulitis & Pregnancy \\
\hline & Pancreatic cancer & Factor II gene mutation & Pancreatititis & Oral contraceptives \\
\hline & Gastrointestinal cancer & $J A K 2$ gene mutation & Appendicitis & Idiopathic \\
\hline & Malignant lymphoma & Protein $\mathrm{C}$ deficiency & Inflammatory bowel disease & \\
\hline & Other primary cancer & Protein S deficiency & Connective tissue disease & \\
\hline & & Antithrombin III deficiency & Cytomegalovirus/HIV infection & \\
\hline & & Acquired thrombophilic disorders & Tuberculus lymphadenitis & \\
\hline & & $\begin{array}{l}\text { Primary myeloproliferative } \\
\text { disorders }\end{array}$ & Abdominal surgery and trauma & \\
\hline & & $\begin{array}{l}\text { Paroxysmal nocturnal } \\
\text { hemoglobinemia }\end{array}$ & $\begin{array}{l}\text { Omphalitis/neonatal umbilical } \\
\text { sepsis }\end{array}$ & \\
\hline & & Antiphospholipid syndrome & & \\
\hline & & Hyperhomocysteinemia & & \\
\hline & & Increased factor VIII levels & & \\
\hline & & $\begin{array}{l}\text { Thrombin activatable fibrinolysis } \\
\text { inhibitor gene }\end{array}$ & & \\
\hline
\end{tabular}

\section{Epidemiology}

PVT prevalence is estimated to be $0.6-15.8 \%$ in patients with liver cirrhosis or portal hypertension [6,9,12,13-16]. The prevalence of PVT increases with the severity of cirrhosis. In patients with compensated cirrhosis it has been reported to be from as low as $1 \%[6,12]$ up to $8-25 \%$ in candidates for liver transplantation (LT) $[8,9,14-16]$. In a recent study [17] of 219 cirrhotics awaiting LT, the overall prevalence of PVT was $15.9 \%$, similar to the $8-25 \%$ reported in other series $[8,18]$. Depending on the imaging method used for the evaluation of PVT, the reported prevalence is variable. A prevalence of $10-25 \%$ has been reported by ultrasonography $[8,13,19,20]$. The use of contrast agents in ultrasound has been shown to increase the sensitivity for the detection and characterization of portal thrombi. Spiral computed tomography (CT) was not as sensitive as contrast-enhanced ultrasonography (CEUS) for the further characterization of PVT $(67.6 \%$ vs. $98 \%)$ in the study by Rossi et al [21]. However, dynamic contrast-enhanced magnetic resonance imaging (MRI) and 4-phase multidetector CT are more widely used, as they provide extra information not only about the thrombus extension to the SMV or splenic vein, but also for the diagnosis of HCC.

Considering etiology, alcoholic and hepatitis B virusrelated cirrhosis were found to be the most frequent causes of PVT in 885 candidates for LT [14]. By contrast, in another study of 219 candidates for LT [17] no relation was found between the etiology of liver disease and the prevalence of PVT. Development of PVT is diagnosed mainly in ChildPugh class B and C cirrhotic patients. The frequency of PVT is greater in patients with cirrhosis and HCC, reportedly as high as $35 \%$ [22].

\section{PVT pathophysiology}

PVT formation in cirrhosis is multifactorial (Fig. 1). Increased intrahepatic vascular resistance in combination with reduced portal flow velocity are considered important risk factors for PVT in liver cirrhosis. Two recent studies have addressed the predictive value of reduced portal inflow velocity for the de novo development of PVT in cirrhotics [23,24]. Patients with de novo PVT had lower mean PV flow in comparison with those without. The long-debated argument that non-selective $\beta$-blockers (NSBBs) may induce PVT in liver cirrhosis is also based on the same hypothesis. There is only one small study of 56 patients with liver cirrhosis, evaluated for PVT every 6 months, and the use of NSBBs was found to be an independent predictor of developing PVT [24]; however, further large studies are required.

Cirrhotics have been traditionally considered prone to bleeding due to thrombocytopenia, defects of pro-coagulant factors and fibrinolysis [25]. Recently, however, there is growing evidence that hypercoagulability is an important part of the hematological spectrum in cirrhosis $[5,26]$, supported by the finding of increased thrombin generation in portal blood samples of 28 cirrhotic patients [27]. Kalambokis et al [28] reported that patients with thrombin-antithrombin (TAT) levels above $13.5 \mathrm{ng} / \mathrm{mL}$ had a significantly higher probability of developing PVT, with the limitation of potent impaired clearance rates of TAT due to liver dysfunction. In line with the above, intrinsic resistance to the anticoagulant action of thrombomodulin was associated with de novo PVT [29].

There are limited reports that evaluate the role of factors VIII and von Willebrand in cirrhosis and PVT [30]. In a comparative study of 24 cirrhotic patients with PVT and 


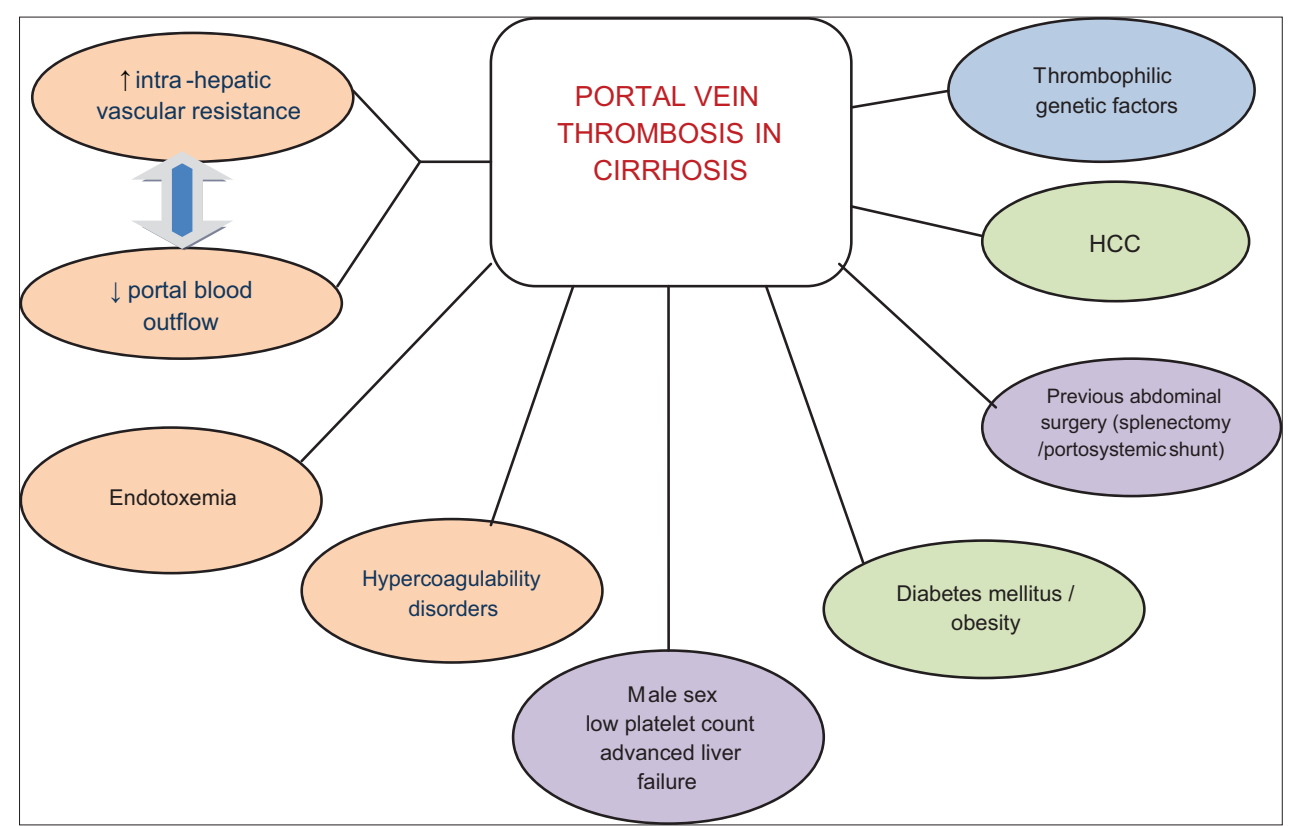

Figure 1 Pathophysiological aspects in portal vein thrombosis in cirrhosis HCC, hepatocellular carcinoma

60 without, activity of ADAMTS-13 (a metalloprotease enzyme that cleaves von Willebrand factor) was found to be independently associated with PVT [31]. On the other hand, factor VIII levels (procoagulant) increase gradually in advanced stages of cirrhosis [32], in contrast to protein C levels (anticoagulant), which become lower [33], giving a ratio indicative of hypercoagulability [5]. Factor V Leiden G1691A, methylenetetrahydrofolate reductase (MTHFR) C677T and prothrombin G20210A mutations have been associated with PVT in cirrhosis $[34,35]$. A recent study highlights the possible implication of high plasma homocysteine in cirrhosis for PVT formation (especially if complicated by HCC) and MTHFR TT status as a possible link between HCC and PVT [36]. Additionally, antiphospholipid antibodies have been associated with an increased risk of PVT in cirrhosis [37]. However, it remains unclear whether this hypercoagulability is simply related to the consequences of synthetic dysfunction, or if there is an extra genetic component.

Endotoxemia may play a pivotal role in activating clotting system in portal and systemic circulation and could represent an underlying mechanism for PVT. Cirrhotics in late stages are prone to infections by intestinal bacteria as a result of bacterial translocation. Inflammation leads to hemodynamic alterations and ultimately to an increase in portal pressure [38-40]. Even though there is evidence that portal endotoxemia may trigger the coagulation cascade in the PV [41], a recent small study in 49 patients with cirrhosis [42] found that endotoxemia and platelet activity were not associated with PVT. Amongst various risk factors for PVT in cirrhosis, endoscopic therapy for esophageal varices (with sclerotherapy or variceal band ligation) $[43,44]$ and a past history of variceal bleeding [8] seem to play a role, especially in patients with genetic thrombophilia. Endothelial damage or endotoxemia following endoscopic sclerotherapy has been incriminated in PVT development in $16 \%$ of cirrhotics, within a mean 16-month follow up [43]. A genetic cause for thrombosis was additionally found in $70 \%$ of patients with liver cirrhosis who developed PV occlusion. However, sclerotherapy was not found to increase the incidence of PVT in cirrhotics, in a prospective controlled study [44].

Previous abdominal surgery, splenectomy and portosystemic-shunt surgery have been reported as determinants of PVT $[12,17,45]$, due to venous injury and disturbance of blood flow after surgical intervention. Other possible factors are male sex, low platelet count, and advanced liver failure $[46,47]$. Ghabin et al reported fatty or cryptogenic liver disease, ascites, diabetes mellitus, and obesity as predictors of PVT after LT in patients without PVT before LT [48].

PVT associated with HCC is frequently identified in cirrhosis. Beyond direct invasion, hemostatic imbalance due to tumor growth is a common mechanism for the thrombotic state that characterizes cancer biology in general. Amongst the factors associated with PVT in HCC are advanced stage, higher Child-Pugh class, major vessel involvement, low serum albumin and high a-fetoprotein (AFP) [49]. It seems that thrombophilic genetic factors (MTHFR C6777TT, prothrombin gene G20210A mutation) may play an additional role [50,51].

A causative relationship between liver fibrosis and PVT in cirrhosis has been proposed. According to this, micro-infarcts resulting from thrombosis of the hepatic and PV branches may cause ischemia and cell death $[52,53]$ that activates the hepatic stellate cells, which transdifferentiate into myofibroblasts and ultimately replace these areas with fibrous tissue, aggravating cirrhosis [54-56]. 


\section{Presentation, diagnosis, and screening}

The clinical presentation of PVT is variable (acute or subacute vs. chronic; occlusive vs. nonocclusive; benign vs. malignant, and intrahepatic vs. extrahepatic) [12,57]. In the acute phase of thrombus formation, if partially occlusive, it may be asymptomatic or may be associated with mild abdominal pain, nausea, vomiting, diarrhea and loss of appetite. However, if complete, PVT may present as abdominal pain, acute or progressive over a few days, and/ or with signs of decompensation of chronic liver disease, including variceal bleeding or ascites. Other symptoms may include bloody diarrhea, symptoms and signs of peritonitis, intestinal ischemia, and portal cholangiopathy. Sudden clinical deterioration in a cirrhotic patient, such as the development of diuretic-resistant ascites or bacterial peritonitis, may be suggestive of the development of PVT and should be thoroughly evaluated. Whenever the occlusion extends to the superior mesenteric vein and mesenteric arches, there is a risk of intestinal infarction that could be life-threatening. Splenic vein involvement may also be present.

The portal hypertensive bleeding risk appears to be more than threefold in patients with PVT and cirrhosis than in patients with cirrhosis alone [58]. In case of an acute complete occlusion of the PV, hepatic arterial vasodilatation is usually able to preserve liver function. After a period of 3-5 weeks, the obstructed part of PV is bypassed through the formation of venous collaterals, known as portal cavernoma. This network of collateral PVs characterizes chronic PVT. Acute or chronic PVT is difficult to define in cirrhosis, because portal hypertension and collaterals may preexist as a result of chronic liver disease.

There are no laboratory findings indicating PVT. Recent studies propose the combination of low D-dimers and elevated protein C plasma concentrations to exclude PVT in cirrhotic patients [46]. Lin et al have demonstrated that increased D-dimer levels and larger diameter of the main PV are independent risk factors for PVT in patients with cirrhosis [59], but there is no standard cutoff to stratify such a risk.

Indeed, in the majority of patients with cirrhosis, PVT is an incidental finding, often during routine ultrasound, CT or MRI evaluation. The first-line technique for PVT detection is Doppler ultrasound. Contrast-enhanced imaging techniques are useful in further characterization of PVT. Intra-thrombus vascularity, observed in the arterial phase of contrast imaging studies, has been reported to be specific for malignant PVT on both CT [60-62] and MRI [63-65]. CEUS seems to be superior to Doppler US for the characterization and further evaluation of PVT, and consequently staging of HCC [45]. In general, the sensitivity range for partial PVT detection for all imaging techniques is rather low (14.3-50\%) [66-68]. Nevertheless, there is no consensus regarding the benefit of systematic screening of cirrhotic patients for PVT [69].

Sarin et al [11] recently suggested a pretest probability assessment based on major (Child's class B or C, prior history of resolved PVT, prothrombotic risk factors such as factor $V$ Leiden mutation, prothrombin gene mutation, MTHFR mutation) and minor (evidence of a large portosystemic shunt, large isolated gastric varices , HCC, previous/or active systemic venous thrombotic events or abortions, acute abdomen, new onset or worsening portal hypertension complications, recent endoscopic, radiological or surgical abdominal interventions, portal flow velocity $<15 \mathrm{~cm} / \mathrm{sec}$ ) criteria. The pretest scoring system requires assessment and validation in prospective clinical studies.

\section{Prognosis and complications}

The impact of PVT on the natural course of cirrhosis and prognosis is still debated. D'Amico et al [58] reported a more than threefold higher risk of failure to control active variceal bleeding in cirrhotic patients with PVT, irrespective of the use of endoscopic hemostasis or surgical shunting. Apart from the greater risk of variceal bleeding et al, Dell'Era highlights the need for longer time to achieve endoscopic eradication of varices due to PVT in cirrhosis [70]. Qi et al suggest a possible new role of occlusive PVT in cirrhosis as an extra marker of decompensated disease and poor prognosis [71]. Most of the individual studies indicate a trend towards worse survival in cirrhotic patients with PVT than in those without PVT, but no significant difference was observed [72]. However, it should be stressed that two large-scale studies did not support the significant associations of PVT with the prognosis of liver cirrhosis $[73,74]$.

Mural or partial PVT does not influence prognosis in contrast to occlusive PVT, which can be deleterious et al $[18,72]$. Non-occlusive PVT may be mostly asymptomatic followed by spontaneous recanalization (up to 70\%). Qi et al suggest that the spontaneous resolution of partial PVT may predict an improvement of liver function in liver cirrhosis [75]. A recent study on natural course of non-malignant partial PVT in cirrhosis showed that, in untreated partial PVT, the progression or regression did not affect the clinical outcome [76].

As expected, the presence of PVT as a major complication of HCC in cirrhosis influences survival, irrespectively of other radiological characterization. Better survival has been found in those patients with normal AFP [77]. According to the Barcelona Clinic Liver Cancer (BCLC) Staging System, HCC with PVT is classified as advanced HCC (BCLC stage C) [78] indicating the importance of differentiation of malignant vs. benign PVT in the management of patients with liver cirrhosis. Neoplastic PV thrombus, occurring in $6.5-44 \%$ of patients with HCC, renders a patient unsuitable for further invasive treatment approaches, because of the high incidence of tumor recurrence $[22,79,80]$. The overall mortality in chronic PVT is less than $10 \%$, but in case of coexistence with cirrhosis and HCC it increases to $26 \%$ [22], making treatment decisions more than crucial.

\section{PVT and LT}

The prevalence of PVT is estimated to be approximately $10 \%$ in patients undergoing LT [8]. In cirrhotic patients 
who are candidates for LT, PVT is associated with greater operative technical difficulties and risk for re-thrombosis. In most cases the operative time is extended, more transfusions are required and there is a greater possibility of reoperation, whereas PVT extension plays a decisive role in the survival rate $[81,82]$. Generally, overall morbidity and mortality in LT recipients of are not influenced by the presence of PVT [83]. However, in a recent meta-analysis [84], it was demonstrated that LT recipients with pre-LT PVT had a significantly lower 1-year survival rate compared to those without (odds ratio [OR] 0.733, 95\% confidence interval [CI] 0.621-0.865). In the subgroup with complete PVT, the prognostic value was more pronounced (OR 0.503, 95\%CI 0.295-0.858), but the impact of PVT on the 5-year survival was not significant.

In practice, PVT can influence the eligibility for LT, especially in cases with extended thrombosis. The preoperative use of anticoagulation seems to reduce the risk of rethrombosis (6.1\% vs. $10.3 \%$ without prior PVT therapy) [18] and prolonged anticoagulation until transplantation, even when re-permeation is recommended [85]. If LT candidates have progressive PVT not responding to anticoagulation, transjugular intrahepatic portosystemic shunting (TIPS) is the alternative option.

Post-transplant PVT can be a complication because of donor/recipient PV diameter mismatch (technical issues), prior splenectomy, pediatric transplantation, and the need for intra-operative PV reconstruction with a vein conduit [86-90]. Incidence rates of post-transplantation PVT have been reported to be as high as $2.5 \%[91,92]$. PVT can significantly reduce graft and patient survival and is associated with high mortality (65-75\%). Delayed PVT, defined as appearing one month after LT, does not necessarily lead to graft failure, and the main consequences are related to portal hypertension. In contrast, early PVT potentially results in re-transplantation if medical and radiological treatment fail.

\section{Primary prevention of PVT in cirrhosis}

A trial by Villa et al [93] has shown that a 12-month daily treatment with enoxaparin 4000 IU in cirrhotics prevented the occurrence of PVT (8.8\% enoxaparin group vs. $27.7 \%$ controls; $\mathrm{P}=0.048$ ), without increasing bleeding complications or decompensation rates. It was also suggested that anticoagulation might play an anti-fibrogenic role, preventing progression to cirrhosis in patients with chronic liver disease [94], but confirmation is required. Another controversial issue is thromboprophylaxis in cirrhotics for prevention of deep vein thrombosis (DVT) [95]. No consensus exists to date on the safety of anticoagulation in hospitalized cirrhotics, because of the lack of randomized controlled trials [10]. Even though several factors, including advanced stage, diabetes mellitus, alcohol etiology and low serum albumin, have been associated with an increased risk of DVT in cirrhosis, it remains unclear which subgroup of patients is likely to benefit from DVT prophylaxis.

\section{Treatment options for PVT in cirrhosis}

Current evidence from case series and observational studies has not provided robust data for the optimal management of PVT in cirrhosis. The main concern with PVT treatment is to balance the bleeding risk [96] against the life-threatening extension of thrombosis (Fig. 2) [97].

\section{Low-molecular-weight heparin (LMWH) and vitamin K antagonists (VKAs)}

A critical issue is which anticoagulation could represent a safer therapeutic option, and when and for how long this treatment should be administered in cirrhotic patients with PVT. Anticoagulation, with LMWH or fondaparinux parenterally, and VKA orally have been used therapeutically in cirrhotic patients with PVT. Drawbacks include the subcutaneous administration and the presence of ascites in weight-adjusted dose for LMWH and close monitoring of the international normalized ratio (INR target range: 2-3 based on empirical rules), dietary limitations and interference with model for end-stage liver disease score for VKA. Cirrhosis affects coagulation tests, increasing INR and activated partial thromboplastin time (aPTT) and decreasing anti-Xa. Several studies have even documented a correlation between higher INR levels and increased severity of cirrhosis [98-101]. This makes therapeutic drug monitoring difficult to interpret and optimize because INR elevation caused by warfarin cannot be differentiated from progression of the underlying disease. Intravenous administration of unfractionated heparin (UFH) is not indicated, because baseline aPTT in cirrhosis is often prolonged well above normal values and therefore the effective dosage will probably be underestimated. The aPTT test has not been assessed in cirrhotic patients and the target aPTT range is unclear in this group of patients [98-101]. UFH cannot be used practically and conveniently for long-term treatment; nevertheless, it could be a potential option in patients with concomitant renal failure and/or hemodynamic instability.

The effect of cirrhosis on antithrombin levels and the platelet count, in addition to the presence of renal failure or bacterial infections, should always be taken into consideration, as they may provoke an added risk for bleeding complications. According to the recent guidance published by the Anticoagulation Forum [102], cirrhotic patients with PVT should undergo endoscopic screening of esophageal varices and, if indicated, banding treatment should precede the LMWH treatment (either prophylactic doses or half therapeutic doses depending on the platelet count).

Recommendations for anticoagulation treatment based on the Baveno VI Consensus Workshop [10] highlight the need for individualization of treatment. LT candidates should be on anticoagulation until transplantation to prevent re-thrombosis. If they remain untreated, an ultrasound follow up every 3 months or CT imaging every 6 months should be performed. In case of thrombosis extension, immediate use of anticoagulation 


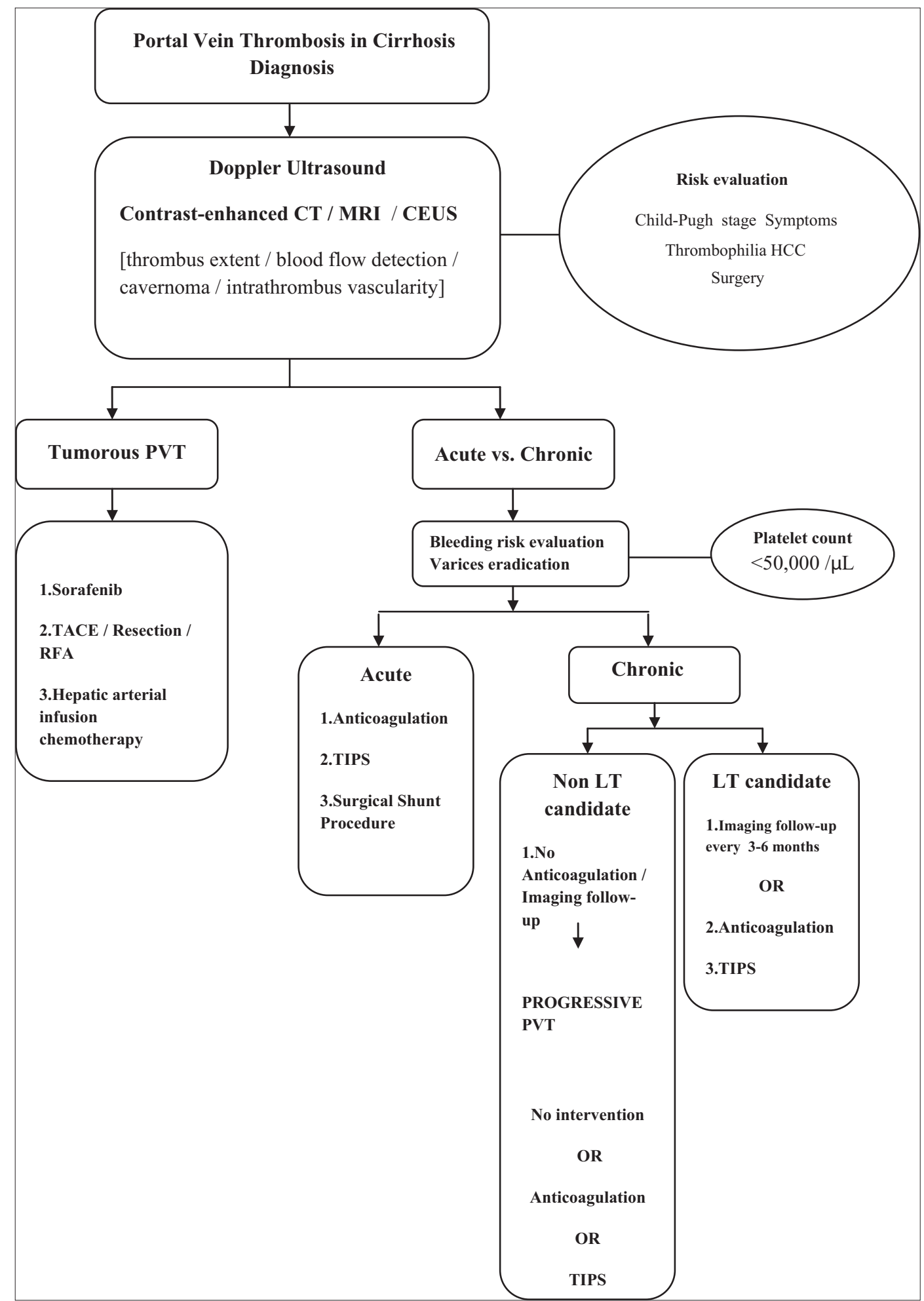

Figure 2 Portal vein thrombosis in cirrhosis: algorithm for diagnosis and treatment

CT, computed tomography; MRI, magnetic resonance imaging; CEUS contrast-enhanced ultrasonography; HCC, hepatocellular carcinoma; PVT, portal vein thrombosis; TACE, transarterial chemoembolization; RFA, radiofrequency ablation; TIPS, transjugular intrahepatic portosystemic shunt; LT, liver transplantation

is recommended. Comorbidities predisposing to prothrombotic conditions or extended PVT are among the factors that physicians should take into account, even in non-LT candidates for anticoagulation as a therapeutic option. On the other hand, 
according to the guidelines of the American Association for the Study of Liver Diseases, acute PVT should be treated for at least 3 months with LMWH and switched to oral anticoagulant agents after patient stabilization. In fact, randomized controlled trials of anticoagulation therapy for the prevention of recurrent thrombosis are lacking in cirrhotic PVT.

Several small clinical studies have assessed the impact of anticoagulation on recanalization rate and bleeding complications (Table 2). Senzolo et al [103] have demonstrated in 56 cirrhotic patients with PVT that anticoagulation is associated with better recanalization rates and fewer portal hypertension complications. A retrospective study by Delgado et al [104] demonstrated a $60 \%$ rate of partial or complete recanalization among 55 selected cirrhotic patients with PVT treated early with LMWH or VKA, findings in accordance with a previous study of 251 cirrhotics, candidates for LT, performed by Francoz et al [8]. Data from a recent multicenter study [105] including 76 cirrhotic patients with PVT, 51 of them on anticoagulation (LMWH or warfarin), confirms the low risk of life-threatening gastrointestinal bleeding events. In this study survival was inferior for treated patients (median 15 months) albeit not statistically significantly $(\mathrm{P}=0.311)$, and $\mathrm{PV}$ patency was achieved in $28.5 \%$ of treated patients $(\mathrm{P}=\mathrm{NS})$.

The main threat for patients on anticoagulation is bleeding. Recent studies support the view that cirrhosis itself is the major cause of bleeding, rather than anticoagulation, which has been associated with a lower risk of both major bleeding and vascular events [106,107]. Cui et al [108] demonstrated that the non-variceal bleeding risk was higher in patients receiving a once-daily high dose of LMWH (1.5 mg/kg), corroborating the use of a standard twice-daily dose. However, the lack of a reliable test to quantify and adjust the dose of LMWH prevents optimization of therapeutic strategies. Measurement of thrombin generation might be an option, but further investigation is required on this topic. Although Delgado et al pointed out that VKA-treated patients had higher rates of bleeding events compared to a LMWH study group [104], anticoagulation for PVT in cirrhotics does not generally change the outcome of upper gastrointestinal bleeding [109] and has been proven relatively safe [101], according to more recent studies. It should be noted, however, that spontaneous resolution of PVT in cirrhosis has been stressed in the literature [110]. In these cases, PVT was associated with a self-limiting underlying pathology or minimal thrombus extension. Given the complexity of cirrhosis, it is not always easy to predict the outcome of untreated PVT $[111,112]$.

\section{Direct oral anticoagulants (DOACs)}

There is a growing interest in DOACs in PVT (Table 3), but clinical data in cirrhosis are scarce [113-118]. Rivaroxaban and apixaban (factor Xa inhibitors) and dabigatran (thrombin inhibitor) are among the new agents that have been used in the 63 cases of acute or chronic PVT in cirrhosis reported up to date. Recent studies have shown that the in vitro anticoagulant potency of apixaban and rivaroxaban is substantially reduced in patients with moderate and advanced cirrhosis [119-120]. These results imply the added safety in terms of bleeding due to overcoagulation, provided drug levels remain in the target range, by monitoring anti-Xa levels. A retrospective study of 20 cirrhotic patients on DOACs compared with 19 cirrhotic patients on LMWH or VKA treatment for multiple different indications showed that these new agents had similar safety characteristics [115]. Recently, Hum et al [121] reported fewer major bleeding events on DOACs compared to VKA or LMWH, along with comparable efficacy in preventing stroke or thrombosis in patients with cirrhosis. De Cottardi et al [122] studied 36 patients with cirrhosis (Child-Pugh score $<$ C), $61 \%$ of them with PVT, the majority treated with lower doses of DOAC. The incidence of complications, including bleeding episodes, related to anticoagulation in this study was similar in patients with or without cirrhosis. In a recent case report, Yang et al [123] pointed out the efficacy of rivaroxaban in achieving complete resolution of recurrent PVT after a 3-month cessation of warfarin in a cirrhotic patient.

A very recent meta-analysis [124] suggests that overall the administration of anti-coagulants in PVT is beneficial, without major bleeding episodes or increased variceal bleeding; therefore, it is highly recommended.

\section{TIPS}

TIPS is considered an effective alternative therapy for chronic PVT in selected patients with decompensated cirrhosis, including: a) patients with symptomatic portal hypertension (variceal bleeding or tense ascites without prior use of anticoagulants) [125]; b) extended and occlusive thrombosis not responding to conventional anticoagulants [126]; and c) large varices unresponsive to $\beta$-blockers or banding ligation, in which anticoagulation would be an extra bleeding risk. TIPS reconstructs PV flow, resulting in a reduction in complications of portal hypertension, decreases the rate of thrombosis progression, and may lead to complete recanalization of the portal tract. In general, the technical complexity of the TIPS procedure is greater in the case of PVT because the intrahepatic branches of the PV may be narrow or occluded. Early TIPS intervention is indicated $[127,128]$ to limit technical failure rates due to upcoming cavernoma formation.

TIPS in cirrhotics with PVT seems to be important in pre-transplant candidates, especially in cases with extended thrombosis with cavernoma. A recent study evaluated 70 cirrhotics with non-tumoral PVT treated with TIPS for portal hypertensive complications (48 bleeding, 18 ascites, or hydrothorax) [127]. After TIPS, complete PV recanalization was found in $57 \%$ of patients, partial recanalization in $30 \%$, whereas no improvement was observed in $13 \%$ of patients. The rate of TIPS dysfunction at 12 and 24 months was 38\% and $85 \%$ for bare stents and $21 \%$ and $29 \%$ for covered stents $(\mathrm{P}=0.001)$, respectively. Patients' survival at 1, 12, and 24 months was $99 \%$, $89 \%$, and $81 \%$, respectively, indicating an excellent long-term outcome. Zhao et al [129], in a large retrospective study of 191 cirrhotic patients with PVT, concluded that appropriate TIPS 


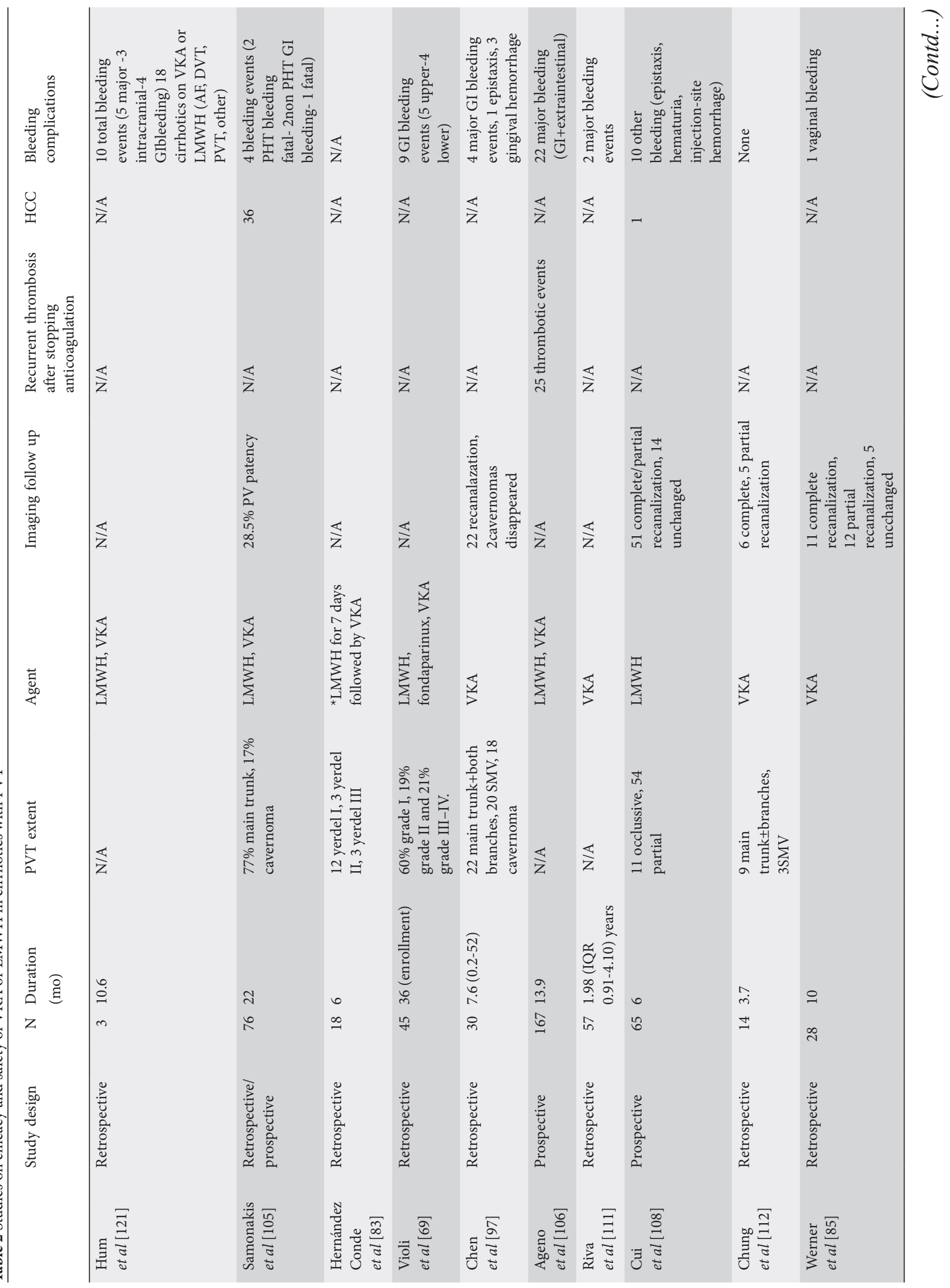




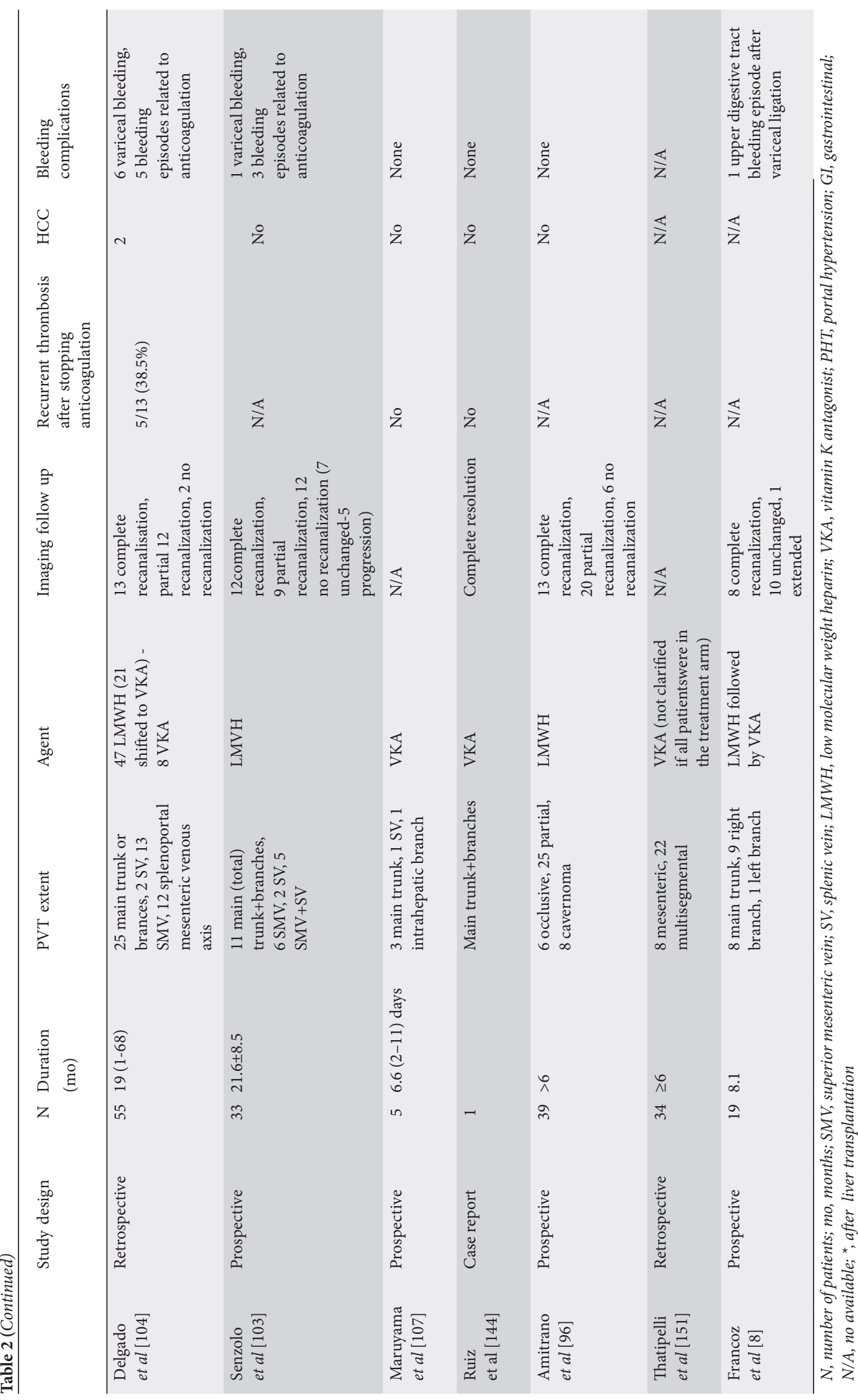


10 A. Mantaka et al

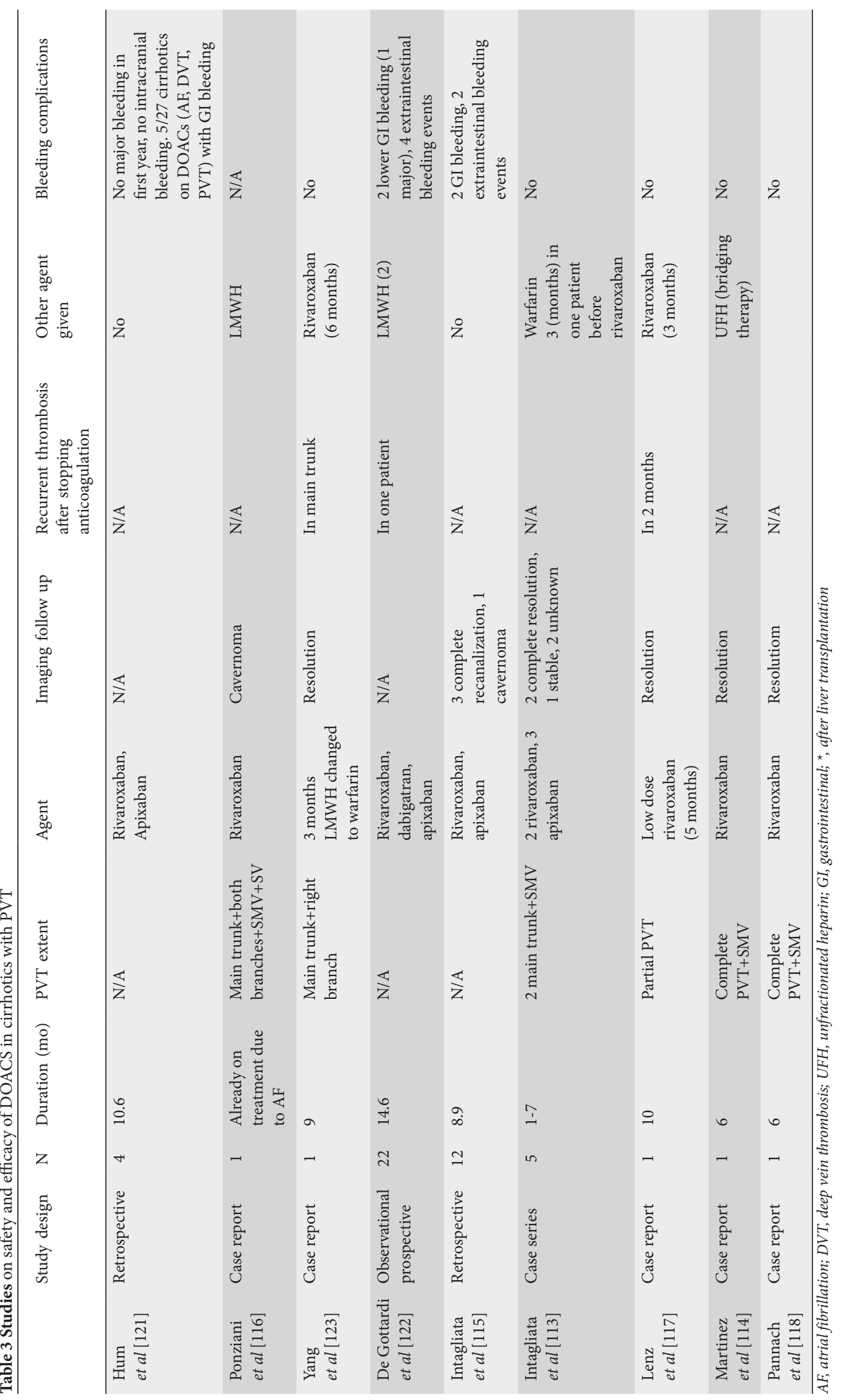


procedures and a lower grade of PVT are essential for a better TIPS technical success rate.

On the other hand, perioperative PVT complicates LT and increases post-transplant morbidity, graft loss and mortality [130133]. There are concerns from recent studies that LT after TIPS is related to a higher complication rate, usually caused by a misplacement of the stent, but overall the outcome was not influenced [134-140]. Prospective randomized studies should investigate whether TIPS placement is superior to anticoagulation in the treatment of PVT in cirrhosis. In cases of PVT after LT, combination therapy, including interventional radiology procedures, thrombolysis, endovascular thrombectomy and stent replacement seem to be effective [141-143]. The most frequently used technique is thrombectomy/thromboendovenectomy with an end-to-end donor-recipient portal anastomosis [18].

\section{Neoplastic PVT treatment in cirrhosis}

Distinguishing benign from malignant PVT is critical to determine the management and therapeutic options, although it is not always easy [144]. Up to $72.7 \%$ of portal thrombi in HCC patients are indeed non-neoplastic PVT. Intra-thrombus vascularity, observed in the arterial phase of imaging studies after the administration of contrast, is a sign implying malignant PVT on both CT and MRI. Blunt thrombi are avascular and will not enhance during contrast-enhanced ultrasound examination, while a hyperenhancement pattern of the portal thrombus in the arterial phase, with "wash out" in the portal or late phase is suggestive of malignant PVT. In cases where neoplastic involvement in PVT cannot be excluded by imaging, differentiation may be achieved by CEUS-guided fine-needle biopsy [145].

Considering therapeutic approaches, the European and American guidelines suggest sorafenib as the treatment of choice for cases involving vascular invasion BCLC stage C. The Japanese guidelines also recommend transarterial chemoembolization or resection in the case of minor vascular invasion and hepatic arterial infusion chemotherapy in the case of major vascular invasion [78,146,147].

Emerging evidence shows that selected patients could benefit from more aggressive treatment approaches. Patients with small HCC and PV obstruction can be safely treated with RFA [148] or yttrium-90 glass microspheres (Theraspheres) in cases of PV obstruction without cavernous transformation [149]. Likewise, conformal radiotherapy induced a $45.8 \%$ objective response rate for PV obstruction in HCC and may be considered an important treatment option [150]. Considering that HCC with PVT is a different type of advanced HCC, additional investigation is necessary to design more personalized treatment options and better management of these difficult to treat patients.

\section{Concluding remarks}

PVT in cirrhosis still has many unanswered questions. PVT is a relatively frequent event in advanced cirrhosis with severe portal hypertension, but also occasionally in early stages, in patients with a high level of systemic inflammation. Standard laboratory coagulation tests are unable to predict bleeding and are inadequate for the assessment of hemostatic status in cirrhotic patients; hence, more comprehensive tests are required to guide the management of thrombotic and bleeding complications. The importance of early detection of PVT led to a pretest scoring system to predict the probability of future or present PVT formation, but it needs to be assessed in prospective clinical studies.

Treatment is difficult because of the heterogeneity of patients with PVT. When cavernous transformation has occurred, prophylactic anticoagulation is reserved only for patients with thrombophilic conditions and/or a high risk of thrombus extension into the superior mesenteric vein [151]. LT candidates should be carefully monitored, since PVT complicates the surgical procedure and anticoagulation is frequently required. A strict three-monthly imaging follow up should be performed to detect extension of the thrombus in cases without anticoagulation during the pre-transplantation period [10]. There is sufficient evidence for interventional therapy such as TIPS, despite its technical difficulties.

The use of anticoagulants in asymptomatic patients with decompensated cirrhosis, or patients with clinically significant PHT and cavernomatous transformation is controversial. Recent studies confirm the safety and efficacy of VKA or LMWH in cirrhosis. Results of clinical trials of DOACs in cirrhotics with PVT are pending, in order to determine their efficacy and safety. Furthermore, the treatment subgroups most likely to reap maximum benefit should be identified, allowing for a personalized management of PVT in cirrhosis.

\section{References}

1. Rottenstreich A, Elazary R, Kalish Y. Abdominal thrombotic complications following bariatric surgery. Surg Obes Relat Dis 2017;13:78-84.

2. El Lakis MA, Pozzi A, Chamieh J, Safadi B. Portomesenteric vein thrombosis after laparoscopic sleeve gastrectomy and laparoscopic Roux-en-Y gastric bypass: a 36-case series. Surg Endosc 2017;31:1005-1011.

3. Shimada T, Maruyama H, Kondo T, et al. Clinical features and natural history of portal vein thrombosis after radiofrequency ablation for hepatocellular carcinoma in Japan. Hepatol Int 2013;7:1030-1039.

4. Matsumoto $\mathrm{K}$, Yamao $\mathrm{K}$, Ohashi $\mathrm{K}$, et al. Acute portal vein thrombosis after EUS-guided FNA of pancreatic cancer: case report. Gastrointest Endosc 2003;57:269-271.

5. Tripodi A, Anstee QM, Sogaard KK, Primignani M, Valla DC. Hypercoagulability in cirrhosis: causes and consequences. $J$ Thromb Haemost 2011;9:1713-1723.

6. Okuda $\mathrm{K}$, Ohnishi $\mathrm{K}$, Kimura $\mathrm{K}$, et al. Incidence of portal vein thrombosis in liver cirrhosis. An angiographic study in 708 patients. Gastroenterology 1985;89:279-286.

7. Yamashita Y, Bekki Y, Imai D, et al. Efficacy of postoperative anticoagulation therapy with enoxaparin for portal vein thrombosis after hepatic resection in patients with liver cancer. Thromb Res 2014;134:826-831.

8. Francoz C, Belghiti J, Vilgrain V, et al. Splanchnic vein thrombosis 
in candidates for liver transplantation: usefulness of screening and anticoagulation. Gut 2005;54:691-697.

9. Yerdel MA, Gunson B, Mirza D, et al. Portal vein thrombosis in adults undergoing liver transplantation: risk factors, screening, management, and outcome. Transplantation 2000;69:1873-1881.

10. de Franchis R; Baveno VI Faculty. Expanding consensus in portal hypertension: Report of the Baveno VI Consensus Workshop: Stratifying risk and individualizing care for portal hypertension. $J$ Hepatol 2015;63:743-752.

11. Sarin SK, Philips CA, Kamath PS, et al. Toward a comprehensive new classification of portal vein thrombosis in patients with cirrhosis. Gastroenterology 2016;151:574-577.

12. Amitrano L, Guardascione MA, Brancaccio V, et al. Risk factors and clinical presentation of portal vein thrombosis in patients with liver cirrhosis. J Hepatol 2004;40:736-741.

13. Gaiani S, Bolondi L, Li Bassi S, Zironi G, Siringo S, Barbara L. Prevalence of spontaneous hepatofugal portal flow in liver cirrhosis. Clinical and endoscopic correlation in 228 patients. Gastroenterology 1991;100:160-167.

14. Nonami T, Yokoyama I, Iwatsuki S, Starzl TE. The incidence of portal vein thrombosis at liver transplantation. Hepatology 1992;16:1195-1198.

15. Charco R, Fuster J, Fondevila C, Ferrer J, Mans E, GarcíaValdecasas JC. Portal vein thrombosis in liver transplantation. Transplant Proc 2005;37:3904-3905.

16. Manzanet G, Sanjuán F, Orbis P, et al. Liver transplantation in patients with portal vein thrombosis. Liver Transpl 2001;7:125-131.

17. Bagheri Lankarani K, Homayon K, Motevalli D, Heidari ST, Alavian SM, Malek-Hosseini SA. Risk factors for portal vein thrombosis in patients with cirrhosis awaiting liver transplantation in Shiraz, Iran. Hepat Mon 2015;15:e26407.

18. Rodríguez-Castro KI, Porte RJ, Nadal E, Germani G, Burra P, Senzolo M. Management of nonneoplastic portal vein thrombosis in the setting of liver transplantation: a systematic review. Transplantation 2012;94:1145-1153.

19. Amitrano L, Brancaccio V, Guardascione MA, et al. Inherited coagulation disorders in cirrhotic patients with portal vein thrombosis. Hepatology 2000;31:345-348.

20. Fimognari FL, De Santis A, Piccheri C, et al. Evaluation of D-dimer and factor VIII in cirrhotic patients with asymptomatic portal venous thrombosis. J Lab Clin Med 2005; 146:238-243.

21. Rossi S, Ghittoni G, Ravetta V, et al. Contrast-enhanced ultrasonography and spiral computed tomography in the detection and characterization of portal vein thrombosis complicating hepatocellular carcinoma. Eur Radiol 2008;18:1749-1756.

22. Pirisi M, Avellini C, Fabris C, et al. Portal vein thrombosis in hepatocellular carcinoma: age and sex distribution in an autopsy study. J Cancer Res Clin Oncol 1998;124:397-400.

23. Zocco MA, Di Stasio E, De Cristofaro R, et al. Thrombotic risk factors in patients with liver cirrhosis: correlation with MELD scoring system and portal vein thrombosis development. J Hepatol 2009;51:682-689.

24. Pellicelli AM, D’Ambrosio C, Barbaro G, et al. Clinical and genetic factors associated to development of portal vein thrombosis in cirrhotic patients without hepatocellular carcinoma. J Hepatol 2011;54:S77.

25. Caldwell SH, Hoffman M, Lisman T, et al. Coagulation in Liver Disease Group. Coagulation disorders and hemostasis in liver disease: pathophysiology and critical assessment of current management. Hepatology 2006;44:1039-1046.

26. Bianchini M, De Pietri L, Villa E. Coagulopathy in liver diseases: complication or therapy? Dig Dis 2014;32:609-614.

27. Delahousse B, Labat-Debelleix V, Decalonne L, d'Alteroche L, Perarnau JM, Gruel Y. Comparative study of coagulation and thrombin generation in the portal and jugular plasma of patients with cirrhosis. Thromb Haemost 2010;104:741-749.
28. Kalambokis GN, Oikonomou A, Baltayiannis G, Christou L, Kolaitis NI, Tsianos EV. Thrombin generation measured as thrombin-antithrombin complexes predicts clinical outcomes in patients with cirrhosis. Hepatol Res 2016;46:E36-E44.

29. La Mura V, Tripodi A, Tosetti G, et al. Resistance to thrombomodulin is associated with de novo portal vein thrombosis and low survival in patients with cirrhosis. Liver Int 2016;36:1322-1330.

30. Kalambokis GN, Oikonomou A, Christou L, Baltayiannis G. High von Willebrand factor antigen levels and procoagulant imbalance may be involved in both increasing severity of cirrhosis and portal vein thrombosis. Hepatology 2016;64:1383-1385.

31. Lancellotti S, Basso M, Veca V, et al. Presence of portal vein thrombosis in liver cirrhosis is strongly associated with low levels of ADAMTS-13: a pilot study. Intern Emerg Med 2016;11:959-967.

32. Tripodi A, Primignani M, Chantarangkul V, et al. An imbalance of pro- vs anti-coagulation factors in plasma from patients with cirrhosis. Gastroenterology 2009;137:2105-2111.

33. Tripodi A, Primignani M, Lemma L, Chantarangkul V, Mannucci PM. Evidence that low protein C contributes to the procoagulant imbalance in cirrhosis. J Hepatol 2013;59:265-270.

34. Pasta L, Marrone C, D’amico M, et al. MTHFR C677T mutations in liver cirrhosis with and without portal vein thrombosis. Liver Int 2006;26:269-270.

35. Amitrano L, Guardascione MA, Ames PR, et al. Increased plasma prothrombin concentration in cirrhotic patients with portal vein thrombosis and prothrombin G20210A mutation. Thromb Haemost 2006;95:221-223.

36. Ventura P, Venturelli G, Marcacci M, et al. Hyperhomocysteinemia and MTHFR C677T polymorphism in patients with portal vein thrombosis complicating liver cirrhosis. Thromb Res 2016;141:189-195.

37. Romero Gómez M, Suárez García E, López Lacomba D, Marchante I, Grande L, Castro Fernandez M. Antiphospholipid antibodies are related to portal vein thrombosis in patients with liver cirrhosis. J Clin Gastroenterol 2000;31:237-240.

38. Mehta G, Gustot T, Mookerjee RP, et al. Inflammation and portal hypertension - the undiscovered country. J Hepatol 2014;61:155-163.

39. Bellot P, García-Pagán JC, Francés R, et al. Bacterial DNA translocation is associated with systemic circulatory abnormalities and intrahepatic endothelial dysfunction in patients with cirrhosis. Hepatology 2010;52:2044-2052.

40. Steib CJ, Hartmann AC, v Hesler C, et al. Intraperitoneal LPS amplifies portal hypertension in rat liver fibrosis. Lab Invest 2010;90:1024-1032.

41. Violi F, Ferro D, Basili S, et al. Ongoing prothrombotic state in the portal circulation of cirrhotic patients. Thromb Haemost 1997;77:44-47.

42. Wosiewicz P, Żorniak M, Hartleb M, et al. Portal vein thrombosis in cirrhosis is not associated with intestinal barrier disruption or increased platelet aggregability. Clin Res Hepatol Gastroenterol 2016;40:722-729.

43. Amitrano L, Brancaccio V, Guardascione MA, et al. Portal vein thrombosis after variceal endoscopic sclerotherapy in cirrhotic patients: role of genetic thrombophilia. Endoscopy 2002;34:535-538.

44. Politoske D, Ralls P, Korula J. Portal vein thrombosis following endoscopic variceal sclerotherapy. Prospective controlled comparison in patients with cirrhosis. Dig Dis Sci 1996;41:185-190.

45. Danila M, Sporea I, Popescu A, Șirli R. Portal vein thrombosis in liver cirrhosis - the added value of contrast enhanced ultrasonography. Med Ultrason 2016;18:218-233.

46. Zhang DL, Hao JY, Yang N. Value of D-dimer and protein S for diagnosis of portal vein thrombosis in patients with liver cirrhosis. J Int Med Res 2013;41:664-672.

47. Tsochatzis EA, Senzolo M, Germani G, Gatt A, Burroughs AK. 
Systematic review: portal vein thrombosis in cirrhosis. Aliment Pharmacol Ther 2010;31:366-374.

48. Ghabril M, Agarwal S, Lacerda M, Chalasani N, Kwo P, Tector AJ. Portal vein thrombosis is a risk factor for poor early outcomes after liver transplantation: analysis of risk factors and outcomes for portal vein thrombosis in waitlisted patients. Transplantation 2016;100:126-133.

49. Connolly GC, Chen R, Hyrien O, et al. Incidence, risk factors and consequences of portal vein and systemic thromboses in hepatocellular carcinoma. Thromb Res 2008;122:299-306.

50. D’Amico M, Pasta L, Sammarco P. MTHFR C677TT, PAI1 4G4G, V Leiden Q506, and prothrombin G20210A in hepatocellular carcinoma with and without portal vein thrombosis. J Thromb Thrombolysis 2009;28:70-73.

51. Samonakis DN, Koutroubakis IE, Sfiridaki A, et al. Hypercoagulable states in patients with hepatocellular carcinoma. Dig Dis Sci 2004;49:854-858.

52. Wanless IR, Liu JJ, Butany J. Role of thrombosis in the pathogenesis of congestive hepatic fibrosis (cardiac cirrhosis). Hepatology 1995;21:1232-1237.

53. Wanless IR, Wong F, Blendis LM, Greig P, Heathcote EJ, Levy G. Hepatic and portal vein thrombosis in cirrhosis: possible role in development of parenchymal extinction and portal hypertension. Hepatology 1995;21:1238-1247.

54. Anstee QM, Goldin RD, Wright M, Martinelli A, Cox R, Thursz MR. Coagulation status modulates murine hepatic fibrogenesis: implications for the development of novel therapies. $J$ Thromb Haemost 2008;6:1336-1343.

55. Mann J, Mann DA. Transcriptional regulation of hepatic stellate cells. Adv Drug Deliv Rev 2009;61:497-512.

56. Mann DA, Marra F. Fibrogenic signalling in hepatic stellate cells. $J$ Hepatol 2010;52:949-950.

57. Sogaard KK, Astrup LB, Vilstrup H, Gronbaek H. Portal vein thrombosis; risk factors, clinical presentation and treatment. BMC Gastroenterol 2007;7:34.

58. D’Amico G, De Franchis R; Cooperative Study Group. Upper digestive bleeding in cirrhosis. Post-therapeutic outcome and prognostic indicators. Hepatology 2003;38:599-612.

59. Lin GS, Xu Q, Zhao SY, Zhang YX. [Clinical features of liver cirrhosis complicated by portal vein thrombosis and related risk factors]. Zhonghua Gan Zang Bing Za Zhi 2016;24:513-517.

60. Mathieu D, Grenier P, Lardé D, Vasile N. Portal vein involvement in hepatocellular carcinoma: dynamic CT features. Radiology 1984;152:127-132.

61. Taylor CR. Computed tomography in the evaluation of the portal venous system. J Clin Gastroenterol 1992;14:167-172.

62. Tublin ME, Dodd GD 3rd, Baron RL. Benign and malignant portal vein thrombosis: differentiation by CT characteristics. AJR Am J Roentgenol 1997;168:719-723.

63. Zirinsky K, Markisz JA, Rubenstein WA, et al. MR imaging of portal venous thrombosis: correlation with CT and sonography. AJR Am J Roentgenol 1988;150:283-288.

64. Okumura A, Watanabe Y, Dohke M, et al. Contrast-enhanced three-dimensional MR portography. Radiographics 1999;19:973987.

65. Rossi S, Rosa L, Ravetta V, et al. Contrast-enhanced versus conventional and color Doppler sonography for the detection of thrombosis of the portal and hepatic venous systems. AJR Am J Roentgenol 2006;186:763-773.

66. Ravaioli M, Zanello M, Grazi GL, et al. Portal vein thrombosis and liver transplantation: evolution during 10 years of experience at the University of Bologna. Ann Surg 2011;253:378-384.

67. Suarez Artacho G, Barrera Pulido L, Alamo Martinez JM, et al. Outcomes of liver transplantation in candidates with portal vein thrombosis. Transplant Proc 2010;42:3156-3158.

68. Cho JY, Suh KS, Shin WY, Lee HW, Yi NJ, Lee KU. Thrombosis confined to the portal vein is not a contraindication for living donor liver transplantation. World J Surg 2008;32:1731-1737.

69. Violi F, Corazza GR, Caldwell SH, et al; PRO-LIVER Collaborators. Portal vein thrombosis relevance on liver cirrhosis: Italian Venous Thrombotic Events Registry. Intern Emerg Med 2016;11:1059-1066.

70. Dell'Era A, Iannuzzi F, Fabris FM, et al. Impact of portal vein thrombosis on the efficacy of endoscopic variceal band ligation. Dig Liver Dis 2014;46:152-156.

71. Qi X, Bai M, Yang Z, et al. Occlusive portal vein thrombosis as a new marker of decompensated cirrhosis. Med Hypotheses 2011;76:522-526.

72. Qi X, Dai J, Yang M, Ren W, Jia J, Guo X. Association between portal vein thrombosis and survival in non-liver-transplant patients with liver cirrhosis: a systematic review of the literature. Gastroenterol Res Pract 2015;2015:480842.

73. Nery F, Chevret S, Condat B, et al. Groupe d'Etude et de Traitement $\mathrm{du}$ Carcinome Hépatocellulaire. Causes and consequences of portal vein thrombosis in 1,243 patients with cirrhosis: results of a longitudinal study. Hepatology 2015;61:660-667.

74. Berry K, Taylor J, Liou IW, Ioannou GN. Portal vein thrombosis is not associated with increased mortality among patients with cirrhosis. Clin Gastroenterol Hepatol 2015;13:585-593.

75. Qi X, Yang Z, Fan D. Spontaneous resolution of portal vein thrombosis in cirrhosis: where do we stand, and where will we go? Saudi J Gastroenterol 2014;20:265-266.

76. Luca A, Caruso S, Milazzo M, et al. Natural course of extrahepatic nonmalignant partial portal vein thrombosis in patients with cirrhosis. Radiology 2012;265:124-132.

77. Carr BI, Buch SC, Kondragunta V, Pancoska P, Branch RA. Tumor and liver determinants of prognosis in unresectable hepatocellular carcinoma: a case cohort study. I Gastroenterol Hepatol 2008;23:1259-1266.

78. Bruix J, Sherman M; American Association for the Study of Liver Diseases. Management of hepatocellular carcinoma: an update. Hepatology 2011;53:1020-1022.

79. Takizawa D, Kakizaki S, Sohara N, et al. Hepatocellular carcinoma with portal vein tumor thrombosis: clinical characteristics, prognosis, and patient survival analysis. Dig Dis Sci 2007;52:3290-3295.

80. Sakata J, Shirai Y, Wakai T, Kaneko K, Nagahashi M, Hatakeyama K. Preoperative predictors of vascular invasion in hepatocellular carcinoma. Eur J Surg Oncol 2008;34:900-905.

81. Lendoire J, Raffin G, Cejas N, et al. Liver transplantation in adult patients with portal vein thrombosis: risk factors, management and outcome. HPB (Oxford) 2007;9:352-356.

82. Harmanci O, Bayraktar Y. Portal hypertension due to portal venous thrombosis: etiology, clinical outcomes. World J Gastroenterol 2007; 13:2535-2540.

83. Hernández Conde M, Llop Herrera E, de la Revilla Negro J, et al. Prevalence and outcome of portal thrombosis in a cohort of cirrhotic patients undergoing liver transplantation. Rev Esp Enferm Dig 2016;108:716-720.

84. Qi X, Dai J, Jia J, et al. Association between portal vein thrombosis and survival of liver transplant recipients: a systematic review and meta-analysis of observational studies. J Gastrointestin Liver Dis 2015;24:51-59.

85. Werner KT, Sando S, Carey EJ, et al. Portal vein thrombosis in patients with end stage liver disease awaiting liver transplantation: outcome of anticoagulation. Dig Dis Sci 2013;58:1776-1780.

86. Cherukuri R, Haskal ZJ, Naji A, Shaked A. Percutaneous thrombolysis and stent placement for the treatment of portal vein thrombosis after liver transplantation: long-term follow-up. Transplantation 1998;65:1124-1126.

87. Durham JD, LaBerge JM, Altman S, et al. Portal vein thrombolysis and closure of competitive shunts following liver transplantation. $J$ Vasc Interv Radiol 1994;5:611-615.

88. Langnas AN, Marujo W, Stratta RJ, Wood RP, Shaw BW Jr. Vascular 
complications after orthotopic liver transplantation. Am J Surg 1991;161:76-82.

89. Doria C, Marino IR. Acute portal vein thrombosis secondary to donor/recipient portal vein diameter mismatch after orthotopic liver transplantation: a case report. Int Surg 2003;88:184-187.

90. Duffy JP, Hong JC, Farmer DG, et al. Vascular complications of orthotopic liver transplantation: experience in more than 4,200 patients. J Am Coll Surg 2009;208:896-903.

91. You S, He XS, Hu AB, et al. [The analysis of portal vein thrombosis following orthotopic liver transplantation]. Zhonghua Wai Ke Za Zhi 2008;46:176-178.

92. Khalaf H. Vascular complications after deceased and living donor liver transplantation:a single-center experience. Transpl Proc 2010;42:865-870

93. Villa E, Cammà C, Marietta M, et al. Enoxaparin prevents portal vein thrombosis and liver decompensation in patients with advanced cirrhosis. Gastroenterology 2012;143:1253-1260. e1-e4.

94. Anstee QM, Dhar A, Thursz MR. The role of hypercoagulability in liver fibrogenesis. Clin Res Hepatol Gastroenterol 2011;35:526-533.

95. Aldawood A, Arabi Y, Aljumah A, et al. The incidence of venous thromboembolism and practice of deep venous thrombosis prophylaxis in hospitalized cirrhotic patients. Thromb J 2011;9:1.

96. Amitrano L, Guardascione MA, Menchise A, et al. Safety and efficacy of anticoagulation therapy with low molecular weight heparin for portal vein thrombosis in patients with liver cirrhosis. J Clin Gastroenterol 2010;44:448-451.

97. Chen H, Liu L, Qi X, et al. Efficacy and safety of anticoagulation in more advanced portal vein thrombosis in patients with liver cirrhosis. Eur J Gastroenterol Hepatol 2016;28:82-89.

98. Fuentes A, Gordon-Burroughs S, Hall JB, Putney DR, Monsour HP Jr. Comparison of anti-Xa and activated partial thromboplastin time monitoring for heparin dosing in patients with cirrhosis. Ther Drug Monit 2015;37:40-44.

99. Gulley D, Teal E, Suvannasankha A, Chalasani N, Liangpunsakul S. Deep vein thrombosis and pulmonary embolism in cirrhosis patients. Dig Dis Sci 2008;53:3012-3017.

100. Dabbagh O, Oza A, Prakash S, Sunna R, Saettele TM. Coagulopathy does not protect against venous thromboembolism in hospitalized patients with chronic liver disease. Chest 2010;137:1145-1149.

101. Potze W, Arshad F, Adelmeijer J, et al. Routine coagulation assays underestimate levels of antithrombin-dependent drugs but not of direct anticoagulant drugs in plasma from patients with cirrhosis. Br J Haematol 2013;163:666-673.

102. Ageno W, Beyer-Westendorf J, Garcia DA, Lazo-Langner A, McBane RD, Paciaroni M. Guidance for the management of venous thrombosis in unusual sites. J Thromb Thrombolysis 2016;41:129-143.

103. Senzolo M, M Sartori T, Rossetto V, et al. Prospective evaluation of anticoagulation and transjugular intrahepatic portosystemic shunt for the management of portal vein thrombosis in cirrhosis. Liver Int 2012;32:919-927.

104. Delgado MG, Seijo S, Yepes I, et al. Efficacy and safety of anticoagulation on patients with cirrhosis and portal vein thrombosis. Clin Gastroenterol Hepatol 2012;10:776-783.

105. Samonakis DN, Triantos CK, Gatselis N, et al. Treatment of portal vein thrombosis in cirrhosis: a multicenter real life study. Hepatol Intern 2016;10(Suppl 1):P0816.

106. Ageno W, Riva N, Schulman S, et al. Long-term clinical outcomes of splanchnic vein thrombosis: results of an international registry. JAMA Intern Med 2015;175:1474-1480.

107. Maruyama H1, Takahashi M, Shimada T, Yokosuka O. Emergency anticoagulation treatment for cirrhosis patients with portal vein thrombosis and acute variceal bleeding. Scand J Gastroenterol 2012;47:686-691.

108. Cui SB, Shu RH, Yan SP, et al. Efficacy and safety of anticoagulation therapy with different doses of enoxaparin for portal vein thrombosis in cirrhotic patients with hepatitis B. Eur J Gastroenterol Hepatol 2015;27:914-919.

109. Cerini F, Gonzalez JM, Torres F, et al. Impact of anticoagulation on upper-gastrointestinal bleeding in cirrhosis. A retrospective multicenter study. Hepatology 2015;62:575-583.

110. Borja A, Xing W, Lymen E, Azucena B, Sule AA. Thrombus resolution in two patients with portal vein thrombosis without anticoagulation: do we need to anticoagulate patients with portal vein thrombosis? Int J Angiol 2016;25:e93-e96.

111. Riva N, Ageno W, Poli D et al; Italian Federation of Anticoagulation Clinics (FCSA); Italian Federation of Anticoagulation Clinics FCSA. Safety of vitamin K antagonist treatment for splanchnic vein thrombosis: a multicenter cohort study. J Thromb Haemost 2015;13:1019-27.

112. Chung JW, Kim GH, Lee JH, et al. Safety, efficacy, and response predictors of anticoagulation for the treatment of nonmalignant portal-vein thrombosis in patients with cirrhosis: a propensity score matching analysis. Clin Mol Hepatol 2014;20:384-391.

113. Intagliata NM, Maitland H, Northup PG, Caldwell SH. Treating thrombosis in cirrhosis patients with new oral agents: ready or not? Hepatology 2015;61:738-739.

114. Martinez M, Tandra A, Vuppalanchi R. Treatment of acute portal vein thrombosis by nontraditional anticoagulation. Hepatology 2014;60:425-426.

115. Intagliata NM, Henry $\mathrm{ZH}$, Maitland $\mathrm{H}$, et al. Direct oral anticoagulants in cirrhosis patients pose similar risks of bleeding when compared to traditional anticoagulation. Dig Dis Sci 2016;61:1721-1727.

116. Ponziani FR, De Candia E, De Cristofaro R, Pompili M. Portal vein thrombosis occurrence in a cirrhotic patient during treatment with rivaroxaban. Liver Int 2017;37:1251.

117. Lenz K, Dieplinger B, Buder R, Piringer P, Rauch M, Voglmayr M. Successful treatment of partial portal vein thrombosis (PVT) with low dose rivaroxaban. Z Gastroenterol 2014;52:1175-1177.

118. Pannach S, Babatz J, Beyer-Westendorf J. Successful treatment of acute portal vein thrombosis with rivaroxaban. Thromb Haemost 2013;110:626-627.

119. Potze W, Arshad F, Adelmeijer J, et al. Differential in vitro inhibition of thrombin generation by anticoagulant drugs in plasma from patients with cirrhosis. PLoS One 2014;9:e88390.

120. Potze W, Adelmeijer J, Lisman T. Decreased in vitro anticoagulant potency of Rivaroxaban and Apixaban in plasma from patients with cirrhosis. Hepatology 2015;61:1435-1436.

121. Hum J, Shatzel JJ, Jou JH, Deloughery TG. The efficacy and safety of direct oral anticoagulants vs traditional anticoagulants in cirrhosis. Eur J Haematol 2017;98:393-397.

122. De Gottardi A, Trebicka J, Klinger C, et al.; VALDIG Investigators. Antithrombotic treatment with direct-acting oral anticoagulants in patients with splanchnic vein thrombosis and cirrhosis. Liver Int 2017;37:694-699.

123. Yang H, Kim SR, Song MJ. Recurrent acute portal vein thrombosis in liver cirrhosis treated by rivaroxaban. Clin Mol Hepatol 2016;22:499-502.

124. Loffredo L, Pastori D, Farcomeni A, Violi F. Effects of anticoagulants in patients with cirrhosis and portal vein thrombosis: a systematic review and meta-analysis. Gastroenterology 2017;153:480-487.

125. Han G, Qi X, He C, et al. Transjugular intrahepatic portosystemic shunt for portal vein thrombosis with symptomatic portal hypertension in liver cirrhosis. J Hepatol 2011;54:78-88.

126. Qi X, Han G, Fan D. Degree of portal vein thrombosis might be associated with recanalization during anticoagulation. Clin Gastroenterol Hepatol 2012;10:820.

127. Luca A, Miraglia R, Caruso S, et al. Short- and long-term effects of the transjugular intrahepatic portosystemic shunt on portal vein thrombosis in patients with cirrhosis. Gut 2011;60:846-852.

128. Perarnau JM, Baju A, D’alteroche L, Viguier J, Ayoub J. Feasibility 
and long-term evolution of TIPS in cirrhotic patients with portal thrombosis. Eur J Gastroenterol Hepatol 2010;22:1093-1098.

129. Zhao M, Yue Z, Zhao H, et al. Techniques of TIPS in the treatment of liver cirrhosis combined with incompletely occlusive main portal vein thrombosis. Sci Rep 2016;6:33069.

130. Englesbe MJ, Schaubel DE, Cai S, Guidinger MK, Merion RM. Portal vein thrombosis and liver transplant survival benefit. Liver Transpl 2010;16:999-1005.

131. Lendoire J, Raffin G, Cejas N, et al. Liver transplantation in adult patients with portal vein thrombosis: risk factors, management and outcome. HPB (Oxford) 2007;9:352-356.

132. Egawa H, Tanaka K, Kasahara M, et al. Single center experience of 39 patients with preoperative portal vein thrombosis among 404 adult living donor liver transplantations. Liver Transpl 2006;12:1512-1518.

133. Doenecke A, Tsui TY, Zuelke C, et al. Pre-existent portal vein thrombosis in liver transplantation: influence of pre-operative disease severity. Clin Transplant 2010;24:48-55.

134. D’Avola D, Bilbao JI, Zozaya G, et al. Efficacy of transjugular intrahepatic portosystemic shunt to prevent total portal vein thrombosis in cirrhotic patients awaiting for liver transplantation. Transplant Proc 2012;44:2603-2605.

135. Freeman RB Jr, FitzMaurice SE, Greenfield AE, Halin N, Haug CE, Rohrer RJ. Is the transjugular intrahepatic portocaval shunt procedure beneficial for liver transplant recipients? Transplantation 1994;58:297-300.

136. Millis JM, Martin P, Gomes A, et al. Transjugular intrahepatic portosystemic shunts: impact on liver transplantation. Liver Transpl Surg 1995;1:229-233.

137. Chui AK, Rao AR, Waugh RC, et al. Liver transplantation in patients with transjugular intrahepatic portosystemic shunts. Aust N Z J Surg 2000;70:493-495.

138. Tripathi D, Therapondos G, Redhead DN, Madhavan KK, Hayes PC. Transjugular intrahepatic portosystemic stent-shunt and its effects on orthotopic liver transplantation. Eur J Gastroenterol Hepatol 2002;14:827-832.

139. Guerrini GP, Pleguezuelo M, Maimone S, et al. Impact of tips preliver transplantation for the outcome posttransplantation. Am J Transplant 2009;9:192-200.

140. Barbier L, Hardwigsen J, Borentain P, et al. Impact of transjugular intrahepatic portosystemic shunting on liver transplantation: 12-year single-center experience. Clin Res Hepatol Gastroenterol 2014;38:155-163.

141. Cherukuri R, Haskal ZJ, Naji A, Shaked A. Percutaneous thrombolysis and stent placement for the treatment of portal vein thrombosis after liver transplantation: longterm follow-up. Transplantation 1998;65:1124-1126.

142. Baccarani U, Gasparini D, Risaliti A, et al. Percutaneous mechanical fragmentation and stent placement for the treatment of early posttransplantation portal vein thrombosis. Transplantation 2001;72:1572-1582.

143. Kawano Y, Murata S, Taniai N, et al. Interventional treatment of severe portal vein thrombosis after living-donor liver transplantation. J Nippon Med Sch 2016;83:206-210.

144. Ruiz P, Blanco S, Menéndez F, et al. Anticoagulation in a cirrhotic patient with acute portal vein thrombosis unrelated to malignancy. A case report. Rev Esp Enferm Dig 2012;104:152-153.

145. Tarantino L, Francica G, Sordelli I, et al. Diagnosis of benign and malignant portal vein thrombosis in cirrhotic patients with hepatocellular carcinoma: color Doppler US, contrast-enhanced US, and fine-needle biopsy. Abdom Imaging 2006;31:537-544.

146. European Association for the Study of the Liver, European Organisation for Research and Treatment of Cancer. EASLEORTC clinical practice guidelines: management of hepatocellular carcinoma. J Hepatol 2012;56:908-943.

147. Clinical Practice Guidelines for Hepatocellular Carcinoma Differ between Japan, United States, and Europe. Liver Cancer 2015;4:85-95.

148. Neeman Z, Libutti SK, Patti JW, Wood BJ. Percutaneous radiofrequency ablation of hepatocellular carcinoma in the presence of portal vein thrombosis. Clin Imaging 2003;27:417-420.

149. Salem R, Lewandowski R, Roberts C, et al. Use of Yttrium-90 glass microspheres (TheraSphere) for the treatment of unresectable hepatocellular carcinoma in patients with portal vein thrombosis. J Vasc Interv Radiol 2004;15:335-345.

150. Kulik LM, Carr BI, Mulcahy MF, et al. Safety and efficacy of 90Y radiotherapy for hepatocellular carcinoma with and without portal vein thrombosis. Hepatology 2008;47:71-81.

151. Thatipelli MR, McBane RD, Hodge DO, Wysokinski WE. Survival and recurrence in patients with splanchnic vein thromboses. Clin Gastroenterol Hepatol 2010;8:200-205. 